\title{
2 \\ Three common pests of pistachio in California
}

Botrytis cinerea produces spores (conidia) on branched conidiophores (above) and on black sclerotia, which resist environmental stress. White, one-celled Botryosphaeria dothidea spores (below) are produced in flasklike pycnidia. Flasklike perithecia of $B$. dothidea and the ascospores they produce occur in California only on two conifer species: the coast redwood (Sequoia sempervirens) and giant sequoia (Sequoiadendron giganteum).

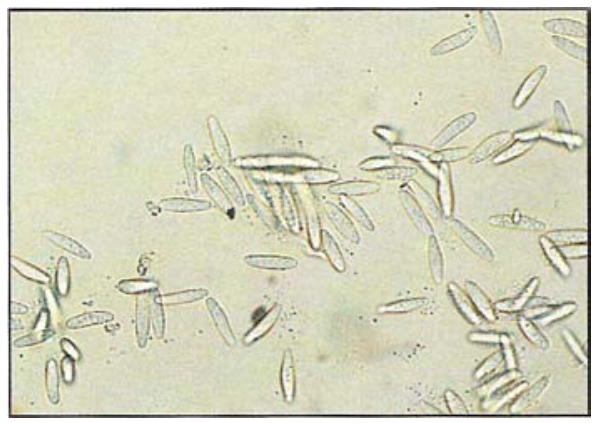

Themis J. Michailides

\section{Similar symptoms do not always indicate the same problem. Only close examination reveals the dif- ference between early Botrytis and Botryosphaeria blights on pista- chio. Later on, Botryosphaeria blight can be confused with an infestation of citrus flat mite.}

In 1983, after heavy, prolonged rains and cool weather, California growers reported a new disease blighting pistachio shoots and flowers. Investigators identified its cause as the asexual stage of grey mold fungus, Botrytis cinerea Pers. Botrytis belongs to the fungal family that causes brown rot of stone fruits (Monilinia fructicola) and that includes the Sclerotinia species.
In 1984, growers observed another disease in two Butte County orchards. Affected trees showed small black spots on the fruit surface and blighting on the branched stems supporting the fruit (California Agriculture, January-February 1985). Isolations from the dead spots, blighted clusters (panicles), and branched stems (rachises) bore the fungus Botryosphaeria dothidea (Moug.:Fr.) Ces. \& de Not. On pistachio trees, the asexual stage of this fungus causes panicle and shoot blight.

These two aerial blight diseases of pistachio have similar symptoms in mid to late spring. Later (from July to September), Botryosphaeria symptoms on rachises and fruits are easily confused with those caused by the citrus flat mite, Brevipalpus lewisi McGregor (Acarina:Tenuipalpidae).

\section{Botrytis cinerea and Botryosphaeria dothidea: early symptoms}
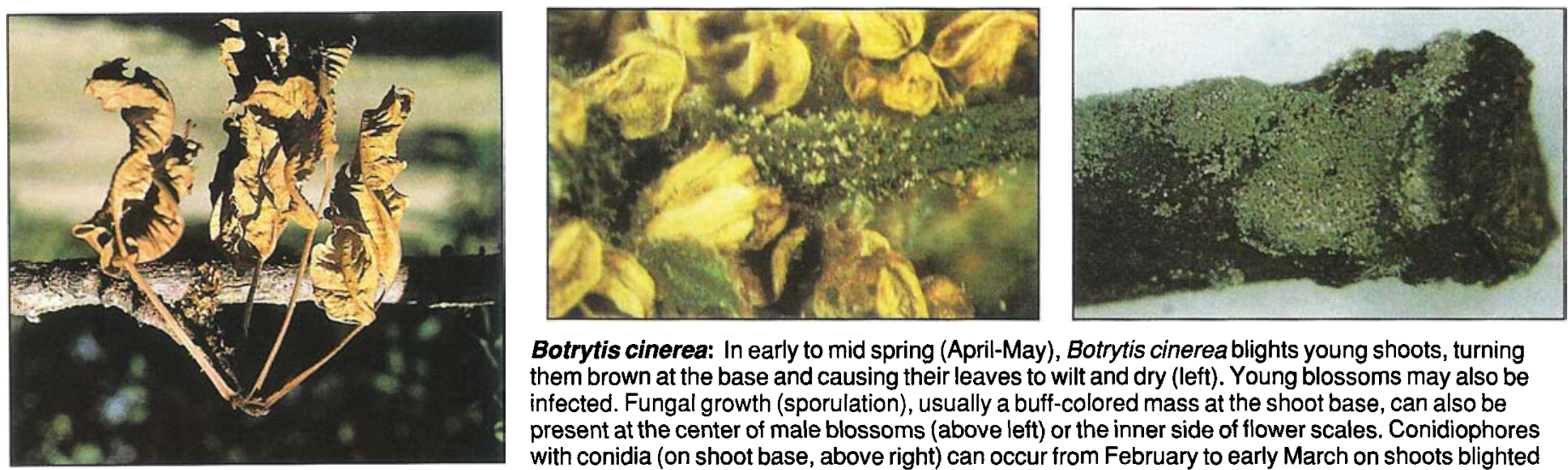

Botrytis cinerea: In early to mid spring (April-May), Botrytis cinerea blights young shoots, turning them brown at the base and causing their leaves to wilt and dry (left). Young blossoms may also be infected. Fungal growth (sporulation), usually a buff-colored mass at the shoot base, can also be present at the center of male blossoms (above left) or the inner side of flower scales. Conidiophores with conidia (on shoot base, above right) can occur from February to early March on shoots blighted during the current or previous spring. If no such sporulation is apparent on the shoot, a fungal sample must be taken to identify the pathogen.
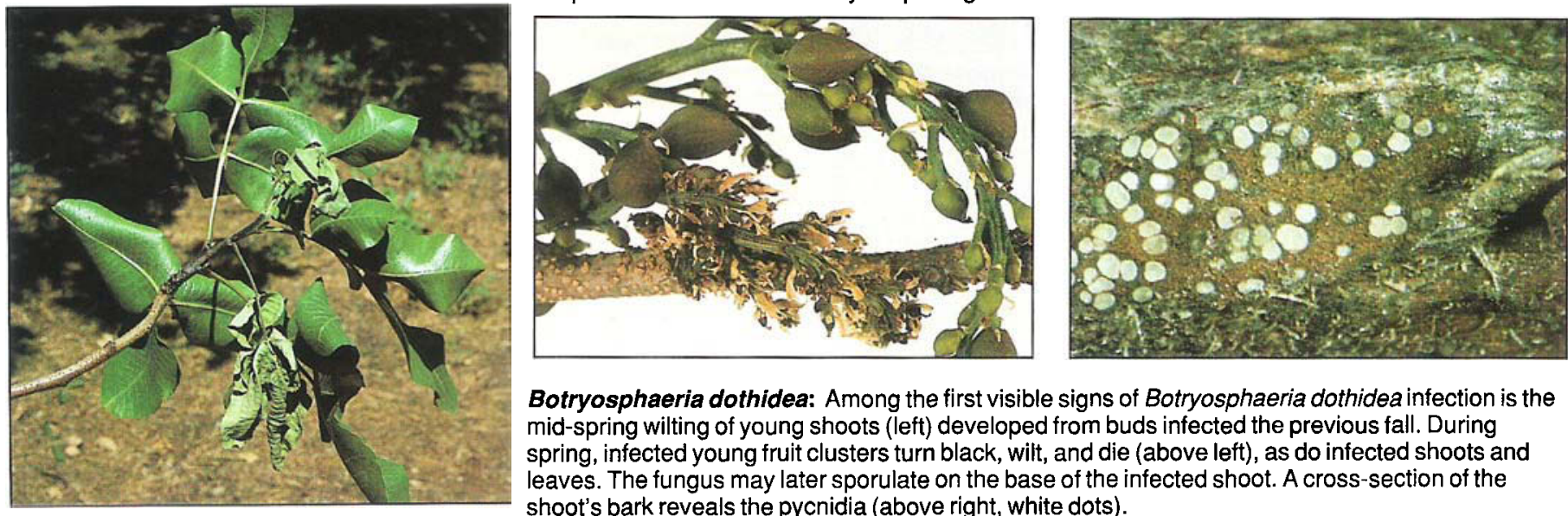

Botryosphaeria dothidea: Among the first visible signs of Botryosphaeria dothidea infection is the mid-spring wilting of young shoots (left) developed from buds infected the previous fall. During spring, infected young fruit clusters turn black, wilt, and die (above left), as do infected shoots and leaves. The fungus may later sporulate on the base of the infected shoot. A cross-section of the shoot's bark reveals the pycnidia (above right, white dots). 
